\title{
An RFLP-Based Technique for Identifying Fungi in the Sooty Blotch and Flyspeck Complex on Apple
}

\author{
K. B. Duttweiler, Department of Plant Pathology, Iowa State University, Ames 50011; G. Y. Sun, College of Plant \\ Protection, Northwest A\&F University, Yangling, Shaanxi, China; and J. C. Batzer, T. C. Harrington, and \\ M. L. Gleason, Department of Plant Pathology, Iowa State University, Ames
}

\begin{abstract}
Duttweiler, K. B., Sun, G. Y., Batzer, J. C., Harrington, T. C., and Gleason, M. L. 2008. An RFLP-based technique for identifying fungi in the sooty blotch and flyspeck complex on apple. Plant Dis. 92:794-799.

A restriction fragment length polymorphism (RFLP)-based technique was developed to identify members of the sooty blotch and flyspeck (SBFS) disease complex on apple because these fungi are difficult to identify using agar-plate isolation and morphological description. The method includes polymerase chain reaction (PCR) amplification of the internal transcribed spacer (ITS) region of ribosomal DNA (rDNA) using a fungal-specific forward primer (ITS1-F) and an SBFS-specific reverse primer (Myc1-R), followed by digestion of the PCR product by the HaeIII restriction enzyme. When applied to previously identified isolates of 24 SBFS-causing species in nine genera, the PCR-RFLP assay produced 14 unique banding patterns. Different genera never shared the same RFLP pattern. To evaluate performance in vivo, the technique was applied to DNA extracted directly from SBFS colonies on apple fruit from three Iowa orchards. The primers amplified the rDNA of only SBFS fungi, with the exception of a Cladosporium sp.; however, its RFLP banding pattern was distinct from those of SBFS fungi. The majority (60\%) of SBFS colonies in the in vivo trial were identified to genus by RFLP analysis. The PCR-RFLP assay greatly streamlined the identification process by minimizing the need for culturing, indicating its value as a tool for field studies of the SBFS complex.
\end{abstract}

Additional keywords: Capnodiales, epiphytic fungi, Mycosphaerellaceae

Sooty blotch and flyspeck (SBFS) is a disease complex of apple (Malus $\times$ domestica Borkh.) caused by epiphytic fungi that blemish the fruit surface. Signs of SBFS fungi appear worldwide in regions with moist climates, during the mid- to late growing season. Because the dark blemishes characteristic of the disease are unappealing to customers, fresh market apple fruit are downgraded to processing use, decreasing crop value by as much as $90 \%$ $(4,31)$. In addition, colonization by SBFS fungi increases desiccation of apple fruit during post-harvest storage (22).

In the $1800 \mathrm{~s}$, SBFS was attributed to a single fungus, Dothidea pomigena Schwein. (24). By the 1920 s, sooty blotch and flyspeck were determined to have distinct causal agents, Gloeodes pomigena (Schwein.) Colby and Schizothyrium pomi (Mont. \& Fr.) Arx, respectively (5,31). Several sooty blotch mycelial types were described in 1933 by Groves (9). In the 1990 s, it was suggested that the variation in mycelial types was not due to environ-

Corresponding author: M. L. Gleason

E-mail: mgleason@iastate.edu

Accepted for publication 14 January 2008.

doi:10.1094/PDIS-92-5-0794

(C) 2008 The American Phytopathological Society mental influence on a single pathogen (the previously prevailing hypothesis) but rather to multiple species of fungi causing SBFS signs $(15,16)$. Based on morphological data, three species then were reported to cause sooty blotch: Peltaster fructicola Eric M. Johnson, T. B. Sutton \& Hodges, Leptodontidium elatius (de Hoog) de Hoog, and Geastrumia polystigmatis Bat. \& M. L. Farr (31).

Further investigation revealed a surprisingly large number of fungi involved in the SBFS disease complex. By coupling morphological description with phylogenetic analysis of ribosomal DNA (rDNA), Batzer et al. (3) determined that SBFS in the Midwest is caused by at least 30 species of fungi in 11 anamorph genera. All the Midwestern SBFS species were Dothideomycetes, with the vast majority belonging to the family Mycosphaerellaceae in the order Dothideales, which subsequently has been reclassified to the order Capnodiales (23). Each species was associated with a single mycelial type on apple. This study also redefined SBFS mycelial types to include discrete speck, compact speck, punctate, ramose, ridged honeycomb, and fuliginous (3). The number of species in the disease complex continues to increase as SBFS fungi from Europe, China, and the eastern United States are surveyed (2,6). In 2006, the first SBFS species belonging to the phylum Basidio- mycota, Wallemia sebi (Fr.) Arx, was identified in China (26).

Taxonomic barriers have held back progress in understanding the environmental biology of SBFS fungi, because many identifications made prior to the $1990 \mathrm{~s}$ now appear to be incorrect $(3,31)$. A major impediment is that these fungi are challenging to culture and identify by traditional techniques. Most SBFS fungi grow slowly in culture and are highly sensitive to surface disinfestants; therefore, they often are overgrown by contaminants. Morphology of SBFS fungi in culture often differs radically from that on apple, and most sporulate sporadically or not at all in culture. Mycelial types on apple can be difficult to differentiate, further complicating identification $(1,3,9)$. These limitations, coupled with the immense diversity of the complex, mean that alternative techniques are needed to facilitate rapid and reliable identification.

Current polymerase chain reaction (PCR)-based identification methods for SBFS fungi assess variation in the large subunit (LSU) and internal transcribed spacer (ITS) regions of rDNA $(3,27)$. However, species identification by sequence homology demands substantial time and expense. Species-specific primers could aid the identification process but would be cumbersome to apply to all the species in the complex.

An alternative approach involves the use of restriction fragment length polymorphism (RFLP) of PCR products, as has been done with various plant pathogens and mycorrhizal fungi $(8,11,17,20,21)$. In a preliminary study, Sun et al. (27) developed a PCR-RFLP identification technique for SBFS members that amplified the ITS region using a reverse primer specific to the most commonly identified SBFS fungi paired with a fungal-specific forward primer, followed by digestion with HaeIII or AluI restriction enzymes. However, this assay was performed on only 14 species in seven genera and used only pure cultures. Identification by RFLP analysis of SBFS colonies sampled directly from apple could greatly facilitate field studies by circumventing the need for agar-plate isolation. Several other plant-pathogenic fungi have been identified by PCR-RFLP analysis from in vivo samples $(8,11,17,20)$.

The objective of this study was to determine the ability of a PCR-RFLP assay 
to distinguish members of the SBFS complex in culture and in vivo.

\section{MATERIALS AND METHODS}

SBFS isolates. SBFS fungi were isolated from apple in 2000 from nine orchards in Illinois, Iowa, Missouri, or Wisconsin and identified by morphological characters and rDNA sequence analysis (3; Table 1). These isolates, which had been stored in glycerol at $-80^{\circ} \mathrm{C}$, were grown on potato dextrose agar (PDA; Difco Laboratories, Detroit) at room temperature prior to DNA extraction.

PCR and restriction enzyme digestion. For PCR assays, DNA was extracted from 1- to 6-week-old mycelium on PDA using the PrepMan Ultra Sample Preparation Reagent (Applied Biosystems, Foster City, CA). A minute amount of aerial mycelium was transferred from the PDA plate to a microcentrifuge tube containing $50 \mu \mathrm{l}$ of the PrepMan Ultra extraction fluid using a pipette tip. The complete ITS region

Table 1. Origin, morphology on apple, and size of HaeIII restriction fragments of the internal transcribed spacer (ITS) region of ribosomal DNA of sooty blotch and flyspeck (3)

\begin{tabular}{|c|c|c|c|c|c|c|}
\hline Putative species & Acc. no. ${ }^{w}$ & Mycelial type $^{x}$ & Isolate & Origin & Fragment sizes $(b p)^{y}$ & RFLP type $^{z}$ \\
\hline \multirow{4}{*}{ Schizothyrium pomi (FS1) } & AY598851 & Flyspeck & GTA2a & Illinois & $262,258,91,81$ & A \\
\hline & & & MSTA1a & Wisconsin & $259,205,91,82$ & B \\
\hline & & & MSTA2a & Wisconsin & $262,258,91,81$ & $\mathrm{~A}$ \\
\hline & & & UMA7b & Missouri & $262,258,91,81$ & A \\
\hline \multirow[t]{3}{*}{ Zygophiala sp. FS2 } & AY598854 & Flyspeck & FVA2a & Iowa & $261,258,90,82$ & A \\
\hline & & & MWA6a & Iowa & $261,258,90,82$ & A \\
\hline & & & MWA8b & Iowa & $261,258,90,82$ & A \\
\hline \multirow[t]{3}{*}{ Zygophiala sp. FS3.1 } & AY598853 & Flyspeck & GTA5c & Illinois & $259,205,91,82$ & B \\
\hline & & & GTA8c & Illinois & $259,205,91,82$ & B \\
\hline & & & MSTA8a & Wisconsin & $259,205,91,82$ & $\mathrm{~B}$ \\
\hline \multirow[t]{2}{*}{ Zygophiala sp. FS3.2 } & AY598856 & Flyspeck & MWA1a & Iowa & $261,259,91,82$ & A \\
\hline & & & MWA1d & Iowa & $261,259,91,82$ & A \\
\hline \multirow[t]{3}{*}{ Dissoconium sp. DS1.1 } & AY598874 & Discrete speck & CUB2c & Illinois & $552,91,86,80$ & $\mathrm{C}$ \\
\hline & & & MSTB5b & Wisconsin & $552,91,86,80$ & $\mathrm{C}$ \\
\hline & & & MWB7b & Iowa & $552,91,86,80$ & $\mathrm{C}$ \\
\hline \multirow[t]{2}{*}{ Dissoconium sp. DS1.2 } & AY598875 & Discrete speck & UMB2a & Missouri & $552,91,86,80$ & $\mathrm{C}$ \\
\hline & & & UMB $4 b$ & Missouri & $552,91,86,80$ & $\mathrm{C}$ \\
\hline \multirow[t]{2}{*}{ Dissoconium sp. FG4 } & AY598876 & Fuliginous & MSTF2 & Wisconsin & $247,292,99$ & $\mathrm{D}$ \\
\hline & & & MSTF3b & Wisconsin & $247,292,99$ & $\mathrm{D}$ \\
\hline Dissoconium sp. FG5 & AY598877 & Fuliginous & UIF3a & Illinois & 555,88 & $\mathrm{C}$ \\
\hline \multirow[t]{2}{*}{ Pseudocercospora sp. FG1.1 } & AY598858 & Fuliginous & MWF7a & Iowa & $285,251,91,90$ & $\mathrm{E}$ \\
\hline & & & MSTF5b & Wisconsin & $285,251,91,90$ & $\mathrm{E}$ \\
\hline Pseudocercospora sp. FS4 & AY598857 & Flyspeck & MWA4b & Iowa & $285,251,91,81$ & $\mathrm{E}$ \\
\hline \multirow[t]{4}{*}{ Pseudocercosporella sp. RH1 } & AY598862 & Ridged honeycomb & AHD1a & Missouri & $357,193,90,80$ & $\mathrm{~F}$ \\
\hline & & & GTD2a & Illinois & $357,193,90,80$ & $\mathrm{~F}$ \\
\hline & & & MSTD1a & Wisconsin & $357,193,90,80$ & $\mathrm{~F}$ \\
\hline & & & UMD7a & Missouri & $357,193,90,80$ & $\mathrm{~F}$ \\
\hline \multirow[t]{3}{*}{ Pseudocercosporella sp. RH2.1 } & AY598866 & Ridged honeycomb & AHE9a & Missouri & $359,195,91,81$ & $\mathrm{~F}$ \\
\hline & & & GTE5b & Illinois & $359,195,91,81$ & $\mathrm{~F}$ \\
\hline & & & UMD1a & Missouri & $359,195,91,81$ & $\mathrm{~F}$ \\
\hline \multirow[t]{3}{*}{ Pseudocercosporella sp. RH2.2 } & AY598868 & Ridged honeycomb & GTC1a & Illinois & $357,194,91,81$ & $\mathrm{~F}$ \\
\hline & & & GTC4a & Illinois & $357,194,91,81$ & $\mathrm{~F}$ \\
\hline & & & UMD8b & Missouri & $357,194,91,81$ & $\mathrm{~F}$ \\
\hline \multirow[t]{3}{*}{ Colletogloeum sp. FG2.1 } & AY598870 & Fuliginous & AHF3a & Missouri & $331,193,168,90$ & G \\
\hline & & & AHF4a & Missouri & $331,193,168,90$ & $\mathrm{G}$ \\
\hline & & & UMF4a & Missouri & $331,193,168,90$ & G \\
\hline \multirow[t]{3}{*}{ Colletogloeum sp. FG2.2 } & AY598871 & Fuliginous & CUF3c & Illinois & $329,193,168,91$ & $\mathrm{G}$ \\
\hline & & & MWF1a & Iowa & $329,193,168,91$ & G \\
\hline & & & UMF2a & Missouri & $329,193,168,91$ & G \\
\hline \multirow[t]{2}{*}{ Colletogloeum sp. FG2.3 } & AY598872 & Fuliginous & CUF2d & Illinois & $329,193,168,90$ & G \\
\hline & & & UIF1 & Illinois & $329,193,168,90$ & $\mathrm{G}$ \\
\hline \multirow[t]{3}{*}{ Peltaster fructicola $(\mathrm{P} 1)$} & AY598887 & Punctate & GTE1a & Illinois & 713,72 & $\mathrm{H}$ \\
\hline & & & MSTE10b & Wisconsin & 713,72 & $\mathrm{H}$ \\
\hline & & & UME4a & Missouri & 713,72 & $\mathrm{H}$ \\
\hline \multirow[t]{3}{*}{ Peltaster sp. P2.1 } & AY598888 & Punctate & GTE5a & Illinois & $367,261,163$ & $\mathrm{I}$ \\
\hline & & & GTE6d & Illinois & $367,258,228,179,146$ & $\mathrm{~J}$ \\
\hline & & & AHE5d & Missouri & $367,258,228,179,146$ & $\mathrm{~J}$ \\
\hline Peltaster sp. P2.2 & AY598889 & Punctate & CUE2b & Illinois & $367,258,228,179,146$ & $\mathrm{~J}$ \\
\hline Xenostigmina sp. P3 & AY598878 & Punctate & AHE3a & Missouri & $282,173,146$ & $\mathrm{~K}$ \\
\hline & & & AHE7a & Missouri & $282,173,146$ & $\mathrm{~K}$ \\
\hline Xenostigmina sp. P4 & AY598879 & Punctate & UIE3a & Illinois & $282,173,145$ & $\mathrm{~K}$ \\
\hline Sterile mycelia sp. RS1 & AY598882 & Ramose & PEC6a & Iowa & $281,174,146,91$ & $\mathrm{~L}$ \\
\hline & & & UMC4 & Missouri & $281,174,146,91$ & $\mathrm{~L}$ \\
\hline Sterile mycelia $\mathrm{sp} . \mathrm{RS} 2$ & AY598882 & Ramose & AHC1a & Missouri & $280,145,92,90$ & M \\
\hline & & & $\mathrm{AHC} 4 \mathrm{~b}$ & Missouri & $280,145,92,90$ & M \\
\hline & & & UMC2 & Missouri & $280,145,92,90$ & $\mathrm{M}$ \\
\hline & & & UMC7a & Missouri & $280,145,92,90$ & M \\
\hline Ramularia sp. P5 & AY598873 & Punctate & UME2a & Missouri & $417,249,83$ & $\mathrm{~N}$ \\
\hline
\end{tabular}

${ }^{\mathrm{w}}$ GenBank accession numbers are from Batzer et al. (3), representing the ITS sequence of the species for one specific isolate but not necessarily the isolates used in the testing of the assay.

${ }^{\mathrm{x}}$ Mycelial type on apple.

${ }^{y}$ Fragment sizes were determined from sequence analysis of ITS1-F/Myc1-R amplicons.

${ }^{\mathrm{z}}$ Patterns of restriction fragment length polymorphism (RFLP) fragments are classified by letters A to N. 
(ITS1-5.8S-ITS2) along with a portion of the LSU of rDNA was amplified using the fungal-specific ITS1-F primer (30) and the Myc1-R primer (27). The reverse-primer Myc1-R was designed to represent the most commonly observed species of SBFS fungi in the Midwestern United States based on 14 species in seven genera (3). This primer (5'-ACTCGTCCGAAGGAG CTACG- $3^{\prime}$ ) was designed from the first 20 bp of $28 \mathrm{~S}$ rDNA gene by selecting sequences homologous within the SBFS fungi. The universal fungal primer ITS1-F was selected as the forward primer. Selectivity of the primer was tested with 19 nonSBFS species; 4 species were fungi frequently isolated from apple epicuticle and 15 were cosmopolitan species obtained from culture collections.

The 50- $\mu$ l PCR reaction mixture contained $4 \mathrm{mM} \mathrm{MgCl} 2,10 \times$ Promega buffer, $200 \mu \mathrm{M}$ dNTPs, 0.25 pM each primer, 2 units of Taq polymerase (Promega Corp.,
Madison, WI), and $2 \mu \mathrm{l}$ of DNA extract. To improve amplification for some isolates, the DNA extract was diluted 10-fold and $5 \%$ dimethyl sulfoxide (DMSO) was included in the PCR reaction. Cycling conditions for PCR (Model PCT-100; MJ Research Inc., Waltham, MA) included hot start at $85^{\circ} \mathrm{C}$; initial denaturation at $95^{\circ} \mathrm{C}$ for $95 \mathrm{~s} ; 35$ cycles of denaturation at $95^{\circ} \mathrm{C}$ for $60 \mathrm{~s}$, annealing at $58^{\circ} \mathrm{C}$ for $60 \mathrm{~s}$, and extension at $72^{\circ} \mathrm{C}$ for $60 \mathrm{~s}$; followed by final annealing at $58^{\circ} \mathrm{C}$ for $60 \mathrm{~s}$ and final extension at $72^{\circ} \mathrm{C}$ for $5 \mathrm{~min}$. Amplification was verified by running $10 \mu$ of the PCR product in a $2 \%$ agarose gel (BioRad, Hercules, CA) with $1 \times$ Tris-borate EDTA (TBE), staining with ethidium bromide, and visualizing with ultraviolet light.

Amplified DNA was digested with the restriction enzyme HaeIII (Invitrogen, Carlsbad, CA). Three units of HaeIII were added directly to $20 \mu \mathrm{l}$ of PCR product, which then was incubated at $37^{\circ} \mathrm{C}$ for $2 \mathrm{~h}$.

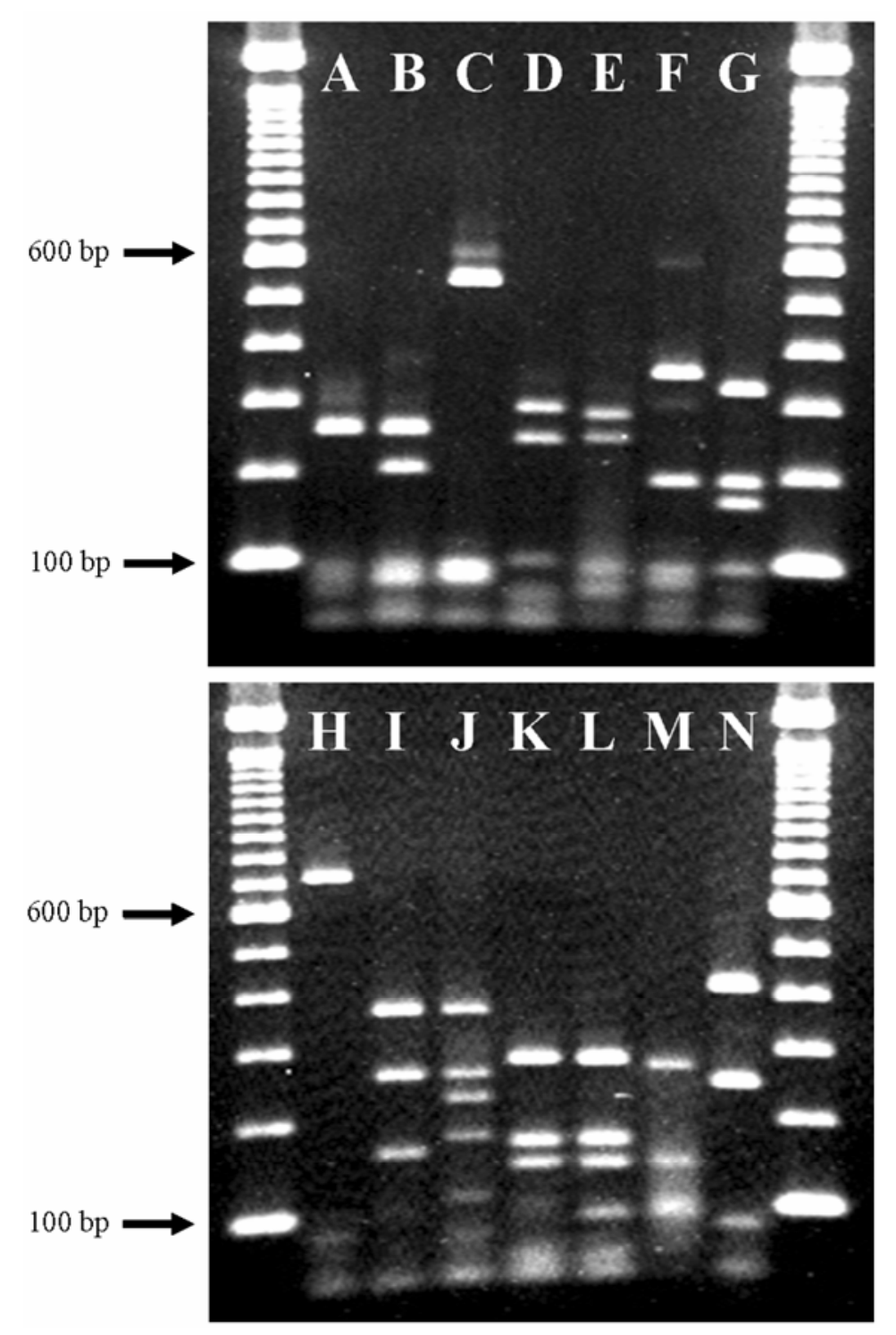

Fig. 1. Fourteen distinct restriction fragment length polymorphism patterns (A-N) after HaeIII digestion of the internal transcribed spacer ribosomal DNA products amplified from pure cultures of sooty blotch and flyspeck fungi. Unmarked lanes are 100-bp-ladders.

Digested PCR products were observed in a $2 \%$ agarose gel, run for $1.75 \mathrm{~h}$ at $150 \mathrm{~V}$ in $1 \times$ TBE buffer, stained with ethidium bromide, and visualized with ultraviolet light. Band patterns were determined against a 1kb-plus ladder using the band-matching feature of the Quantity One software (BioRad). The PCR-RFLP analysis was performed at least twice for all isolates. PCR products were sequenced at the Iowa State University DNA Sequencing and Synthesis Facility. Sequences were edited using Sequence Navigator (Applied Biosystems) and analyzed using BioEdit (10).

SBFS colonies in vivo. SBFS samples were collected from apple fruit in fall 2003 from three orchards near Fort Dodge, Gilbert, and Jefferson, IA. After classification by mycelial type (discrete speck, flyspeck, fuliginous, punctate, ramose, or ridged honeycomb; 3 ), samples were preserved by pressing individual SBFS colonies and supporting apple epidermis between sheets of paper until dry, and then photographed under a dissecting microscope. Each of the 318 preserved samples consisted of a single SBFS colony. The dried samples were stored for 1 to 12 months at room temperature in plastic petri plates before DNA extraction. Fungal DNA was extracted after transferring mycelium scraped from the apple cuticle with a scalpel to PrepMan Ultra Sample Preparation Reagent. Conditions for DNA extraction, PCR, and enzymatic digestion were the same as those described above. Resulting RFLP patterns were compared with patterns observed from cultures of previously identified SBFS species. The PCR products from apple samples that yielded previously unidentified RFLP patterns were sequenced as previously described and subjected to a BLAST search (National Center for Biotechnology Information, Bethesda, MD). To check accuracy and reliability of resulting RFLP patterns, the ITS products of a subsample of colonies on apple were sequenced, edited, and subjected to a BLAST search.

The DNA of each SBFS sample that produced weak or no PCR product with the ITS1-F/Myc1-R primer set was subjected to a second attempt to amplify the ITS region, replacing the Myc1-R primer with a nonspecific reverse primer, ITS4 (30). Other than replacement of the reverse primer, the PCR protocol was performed as described above. The DNA of SBFS samples that did not amplify with either ITS primer set was subjected to another round of PCR in an attempt to amplify the LSU region. The PCR protocol was performed as described above, except that the primer set was LROR/LR5 (29), 5\% DMSO was included, and the annealing temperature was $49^{\circ} \mathrm{C}$. Amplified samples then were sequenced with primers LROR and LR3 and analyzed as described above.

Variation within colonies. To test repeatability of the technique, we evaluated 
whether subsamples of mycelium from single colonies gave consistent results. Seven SBFS colonies on apple were collected and preserved from SBFS-infested fruit in fall 2004 from three orchards in Iowa and stored at room temperature for 18 months. The colonies represented six different mycelial types, and each was divided into four quadrants. Three of the four quadrants from each colony were sampled separately and subjected to the RFLP assay as described above.

\section{RESULTS}

The ITS1-F/Myc1-R primer set amplified the ITS region of each of the 59 SBFS isolates. The amplification products ranged from 784 to $834 \mathrm{bp}$, except that two of the three Peltaster sp. P2.1 isolates and the Peltaster sp. P2.2 isolate produced amplicons of approximately $1,400 \mathrm{bp}$ due to a large insert in the ITS1 region.

Digestion of the amplified products of the pure cultures with HaeIII yielded 14 distinct RFLP patterns. We designated each of the 14 RFLP types by its own letter (Table 1; Fig. 1). All of the RFLP patterns were unique to genus, three were unique to species, and one was unique to an individual isolate. More than one RFLP pattern was observed for four of the nine genera tested. Two pairs of band patterns, RFLP types $\mathrm{D}$ and $\mathrm{E}$ and $\mathrm{K}$ and L (Table 1), were difficult to distinguish visually unless fragments of $100 \mathrm{bp}$ or less were clearly seen (Fig. 1). Intraspecific variability was observed for only two putative species, Zygophiala jamaicensis and Peltaster sp. P2.1. Each RFLP pattern corresponded to a single SBFS mycelial type on apple; however, a mycelial type sometimes corresponded to more than one RFLP pattern.

Validation of RFLP identification in vivo. Of the 318 unidentified SBFS colonies sampled from apple peels, $213(67 \%)$ yielded amplification product using the ITS1-F/Myc1-R primer pair, and 191 (60\% of all colonies, $85 \%$ of those that amplified) produced RFLP patterns matching those of previously identified SBFS fungi (27). Of the 14 RFLP patterns identified from pure culture, 8 (including RFLP types A, C, F, G, K, L, M, and N) were observed among the samples on apple. For each of the observed SBFS RFLP patterns from apple samples, the ITS region of two to nine colonies was sequenced and subjected to a BLAST search. For seven of the eight patterns, the sequences aligned with those of the SBFS species as predicted by RFLP patterns. The only unexpected outcome occurred when the sequences from three SBFS colonies exhibiting the RFLP band pattern of Mycelia sterilia sp. RS2 aligned more closely to $M$. sterilia sp. RS1. Direct comparison of the sequences showed that the majority of the sequences matched $M$. sterilia $\mathrm{sp}$. RS1 and that the variation in RFLP pattern was due to the presence of an extra HaeIII restriction site, as found in
M. sterilia $\mathrm{sp}$. RS2, that was not previously observed.

Nineteen SBFS colonies on apple $(6 \%$ of all colonies, $9 \%$ of the samples that amplified) produced RFLP patterns that did not match those of SBFS fungi. A single amplicon of approximately 790 bp was observed before digestion of all 19 SBFS samples. Of the 19 samples, 6 produced RFLP patterns with a single fragment of approximately $790 \mathrm{bp}, 8$ produced RFLP patterns with two fragments of approximately 790 and $620 \mathrm{bp}$, and 5 produced RFLP patterns with three fragments of approximately 790,710 , and $620 \mathrm{bp}$. The ITS regions of four samples with the single 790-bp RFLP pattern were identical and matched (517/517 bp) Cladosporium tenuissimum (GenBank accession no. AY904056). The ITS regions of two samples with the RFLP pattern including three band fragments were identical to each other, matched closely with the same $C$. tenuissimum (479/480 bp), but shared a single point mutation differentiating these sequences from those with a single-band RFLP pattern.

Of all the apple samples, 71 (37\%) produced RFLPs that included fragment patterns of both a known SBFS fungus and of Cladosporium spp., indicating that these samples included an SBFS species and a Cladosporium sp. The 11 SBFS RFLP patterns observed in the in vivo survey were clearly distinguishable from those of the Cladosporium fragments (Fig. 2).
Three SBFS colonies from apple produced RFLP band patterns that had not been observed previously. Their respective sequences matched most closely with $\mathrm{Pseu}$ docercosporella sp. 4ra (466/468 bp; GenBank accession no. DQ363411), Pseudocercospora sp. 43.1a (441/484 bp; GenBank accession no. DQ363419), and an unnamed fungal endophyte species (421/431 bp, GenBank accession no. AM262372), all of which have been observed to cause SBFS signs in surveys outside the Midwestern United States $(2,6)$.

Of the SBFS colonies on apple, 105 (33\%) either did not amplify an ITS product with the ITS1-F/Myc1-R primer pair or the amplified product did not produce discernible RFLP patterns. Of the 105 samples subjected to PCR using the general ITS or LSU primers, 8 ITS and 24 LSU regions were amplified. The amplified products were sequenced and included multiple incidence of Penicillium spp. (nine LSU and three ITS samples), Athelia spp. (five LSU samples), Tilletiopsis spp. (two ITS and two LSU samples), and single LSU samples of a Exophiala sp., a Stropharia sp., an Acremonium sp., a Bulleromyces sp., and an Aureobasidium $\mathrm{sp}$. The sequences of five samples matched those of known SBFS species, Colletogloeum sp. FG2.3 (one ITS and one LSU sample), Mycelia sterila sp. RS1 (one LSU sample), a Dissoconium sp. (one ITS sample), and a Xenostigmina sp. (one LSU sample); and one sequence matched a Cladosporium sp. (one ITS sample).

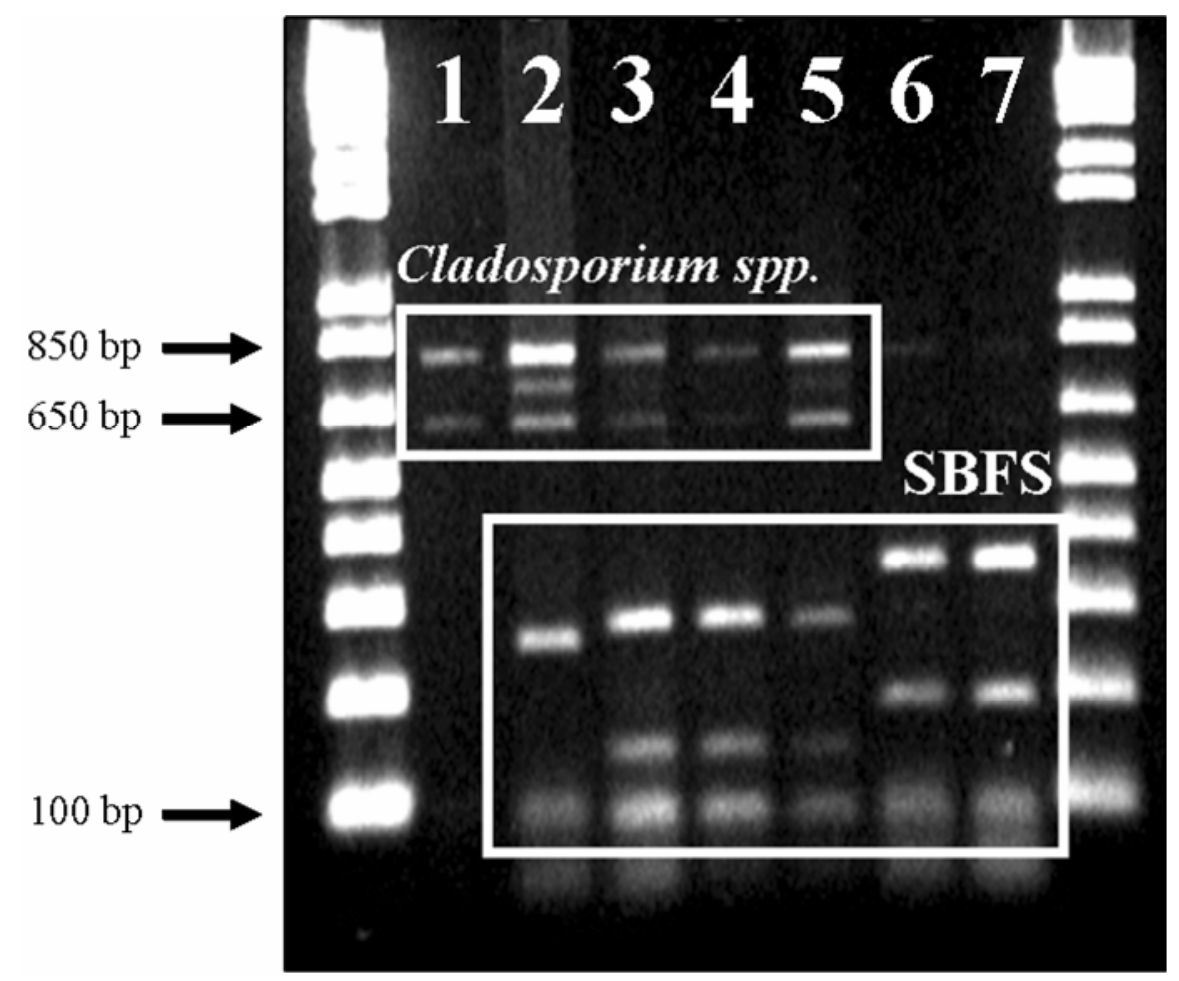

Fig. 2. Lanes 1 to 5 are examples of restriction fragment length polymorphism patterns after HaeIII digestion of the internal transcribed spacer ribosomal DNA products amplified from colonies on apple including both sooty blotch and flyspeck fungi and Cladosporium sp.; unmarked lanes are 1-kb-plus ladders. 
The results of the validation of RFLP identification in vivo are summarized in Table 2 .

Variation within colonies. In each of the seven SBFS colonies on apple that were assayed, all three of the quadrants sampled from the same colony produced identical RFLP patterns (K. B. Duttweiler, unpublished data).

\section{DISCUSSION}

The tested PCR-RFLP assay is substantially faster, simpler, and more reliable than culturing for identification of colonies of SBFS fungi. The assay rapidly and accurately identified the genera of SBFS fungi found on apple in the Midwestern United States. The RFLP band patterns corresponded to the known SBFS morphology and were useful for distinguishing among similar-looking mycelial types on apple (3). As indicated by sequence analysis of a subsample of SBFS colonies from the in vivo study, the technique was consistently accurate. By circumventing agarplate isolation, the in vivo assay reduced the time needed for identification from weeks or months to hours. The RFLPbased identification method is also simpler than traditional methods, which require extensive training in recognizing subtle morphological differences in cultures. In addition, the identification rate of SBFS fungi from colonies on apple was increased from $<35 \%$ using agar-plate isolation (3) to at least $60 \%$ using the RFLP assay.

Traditional identification methods, including determination of growth rate, morphology, and sporulation in vivo and in vitro, have contributed to misidentification of SBFS fungi for 180 years $(1,5)$. For the vast majority of SBFS fungi, it is impossible to identify to genus (let alone species) based on morphology in vivo, and it can be done in vitro only when sporulation occurs (a rare event in many species) or if the rDNA of samples is sequenced (3). Knowing the genera of SBFS fungi populating an orchard may prove to be important for management of the disease, because different genera vary in fungicide sensitivity (28) as well as other aspects of environmental biology $(14,25)$.
The RFLP assay described here takes a valuable first step toward genus and species identification, and could be refined by use of additional restriction enzymes to reveal more species-specific banding patterns. For example, some colonies of $M$. sterilia spp. RS1 and RS2 had the same banding patterns after HaeIII digestion but they were differentiated clearly after digestion with the restriction enzyme AluI (27; K. B. Duttweiler, unpublished data). The RFLP technique also could be an essential first step to guide efficient selection of specific primers to confirm species identity.

For identification of SBFS members directly from the apple epidermis, using the ITS1-F/Myc1-R primer pair proved to be a valuable tool that avoids the frustrations and failures that often accompany agarplate isolation of these fungi. The technique was robust to the vast majority of non-SBFS fungi, as observed after using nonspecific fungal primers for the amplification and sequencing of the ITS or LSU regions of the in vivo samples that did not amplify with Myc1-R. Of these PCR products sequenced, $85 \%$ matched most closely to sequences of members of non-SBFS fungi, indicating that the Myc1-R primer did not amplify the non-SBFS fungal epiphytes present in this study. Although the remaining $15 \%$ were SBFS fungi, the Myc1-R primer did not appear to selectively exclude any SBFS species, because the sequences matched SBFS fungi from a diverse array of genera and mycelial types.

Amplification of a Cladosporium sp., which does not cause SBFS, was not surprising because it is closely related to the seven genera of SBFS fungi used to design the Myc1-R primer (within the same order, Capnodiales) and is a common epiphyte (19). Analysis of ITS regions revealed that the sequences of Cladosporium spp. producing a single fragment after digestion with HaeIII differed from those that produced multiple fragments after digestion with HaeIII, and may explain the variability of the observed Cladosporium RFLP patterns. It is likely that future surveys will encounter non-SBFS fungi in the order Capnodiales, in addition to Cladosporium spp. If so, it would be necessary to deter-

Table 2. Summary of the polymerase chain reaction and restriction fragment length polymorphism (RFLP) analysis results of sooty blotch and flyspeck (SBFS) colonies taken directly from apple peels

\begin{tabular}{lcc}
\hline Analysis results $^{\mathbf{y}}$ & $\begin{array}{c}\text { No. of } \\
\text { colonies }^{\mathbf{z}}\end{array}$ & $\begin{array}{c}\text { Percentage of } \\
\text { colonies }^{-}\end{array}$ \\
\hline Amplified using ITS1-F/Myc1-R & 213 & 67 \\
RFLPs matched previously identified SBFS patterns & 191 & 60 \\
RFLPs matched non-SBFS Cladosporium patterns & 19 & 6 \\
RFLPs did not match previously identified SBFS patterns & 3 & 1 \\
Not amplified using ITS1-F/Myc1-R & 105 & 33 \\
No amplification with ITS1-F/ITS4 or LROR/LR5 primer sets & 71 & 22 \\
Sequences matched non-SBFS apple epiphytes & 29 & 9 \\
Sequences matched previously identified SBFS patterns & 5 & 2 \\
\hline
\end{tabular}

${ }^{\mathrm{y}}$ ITS = internal transcribed spacer.

${ }^{z}$ Total number assessed was 318 . mine their RFLP patterns in order to exclude them from SBFS surveys.

This RFLP analysis consistently distinguished SBFS fungi from the non-SBFS Cladosporium sp., even when both were present in the same sample. Therefore, the assay appears to be robust to nontarget organisms, whereas pure SBFS cultures are required for identification using agarplate isolation $(3,15)$.

Three new SBFS RFLP patterns were identified from the survey of in vivo colonies. The ITS sequences of the three samples displaying new band patterns matched closely with fungi previously identified as members of the SBFS complex; however, these fungi had not yet been assayed using the RFLP technique. This finding indicates that the RFLP assay is likely to be useful for identification of SBFS fungi other than those included in this study.

As the RFLP library expands to SBFS members in regions other than the Midwestern United States, the increasing number of band patterns may complicate visual differentiation among similar patterns. In some cases, it may be difficult to distinguish between similar SBFS RFLP patterns unless they are run adjacent to each other in the same gel, which can require additional time and expense (7). It also is possible that additional RFLP patterns of SBFS fungi may resemble those of Cladosporium sp. or other non-SBFS epiphytes. Therefore, it may be helpful to investigate use of additional restriction enzymes in order to increase differentiation among RFLP patterns.

The PCR-RFLP assay has the potential to minimize the misidentification of SBFS species that previously stymied research on this pathosystem. The assay also could be used for rapid identification of samples taken directly from field studies and to expedite identification of pure cultures. Therefore, the technique can become a valuable tool for improving the ecological understanding of the relatively unexplored SBFS complex. For example, SBFS fungi on plum were identified by coupling sequence information, obtained directly from colonies on plum peels using the ITS1F/Myc1-R primer pair, with morphological description of pure cultures from the same peels (18). The RFLP assay also was used to identify SBFS fungi taken directly from stems of woody plants to determine potential reservoir hosts (12). Third, efficacy of artificial inoculation of apple with recently discovered SBFS isolates was evaluated using this assay, and it proved to be especially useful when pure cultures could not be recovered from colonies on apple fruit (13). Additionally, in a field study investigating phenology of appearance of SBFS species on apple in three Iowa orchards, the RFLP assay identified $85 \%$ of 96 samples in 6 days, and up to $92 \%$ after either the addition of 5\% DMSO in the PCR reaction or 10 -fold dilution of extracted 
DNA (25). The increased rate of identification noted in the latter study may be due in part to improving the technique of transferring in vivo SBFS samples to DNA extract fluid, which reduced the presence of plant tissue contaminants during DNA extraction.

\section{ACKNOWLEDGMENTS}

We thank J. Steimel, M. Agudelo, and N. Tatalović for technical assistance; and L. Leandro for thoughtful review of the manuscript.

\section{LITERATURE CITED}

1. Batzer, J. C. 2005. Sooty blotch and flyspeck on apple: expansion of the fungal complex, post-harvest removal, and heterogeneity of apple canopy wetness and its impact on the outcome of a disease-warning system. Ph. D. dissertation, Iowa State University, Ames.

2. Batzer, J. C., Feldmann, T., Gleason, M. L., and Oertel, B. 2006. Comparison of diversity in the sooty blotch and flyspeck apple disease complex in Germany and the U.S.A. based on parsimony analysis of ribosomal DNA. (Abstr.) Phytopathology 96:S10.

3. Batzer, J. C., Gleason, M. L., Harrington, T. C., and Tiffany, L. H. 2005. Expansion of the sooty blotch and flyspeck complex on apples based on analysis of ribosomal DNA gene sequences and morphology. Mycologia 97:12681286.

4. Batzer, J. C., Gleason, M. L., Weldon, B., Dixon, P. M., and Nutter, F. W., Jr. 2002. Evaluation of postharvest removal of sooty blotch and flyspeck on apples using sodium hypochlorite, hydrogen peroxide with peroxyacetic acid, and soap. Plant Dis. 86:13251332.

5. Colby, A. S. 1920. Sooty blotch of pomaceous fruits. Trans. Ill. Acad. Sci. 13:139-179.

6. Díaz, M. M., Batzer, J. C., and Gleason, M. L. 2006. Expansion of the sooty blotch and flyspeck complex on apples in the eastern U.S. based on analysis of ribosomal DNA and fungal morphology. (Abstr.) Phytopathology 96:S29.

7. Fischer, M., and Wagner, T. 1999. RFLP analysis as a tool for identification of lignicolous basidiomycetes: European polypores. Eur. J. For. Pathol. 29:295-304.

8. Glen, M., Tommerup, I. C., Bougher, N. L., and O'Brien, P. A. 2001. Interspecific and in- traspecific variation of ectomycorrhizal fungi associated with Eucalyptus ecosystems as revealed by ribosomal DNA PCR-RFLP. Mycol. Res. 105:843-858.

9. Groves, A. B. 1933. A study of the sooty blotch disease of apples and casual fungus Gloeodes pomigena, Va. Agric. Exp. Stn. Bull. 50:1-43.

10. Hall, T. A. 1999. BioEdit: a user-friendly biological sequence alignment editor and analysis program for Windows 95/98/NT. Nucleic Acid Symp. Ser. 41:95-98.

11. Harrington, T. C., and Wingfield, B. D. 1995. A PCR-based identification method for species of Armillaria. Mycologia 87:280-288.

12. Hemnani, K., Batzer, J. C., Díaz Arias, M. M., Gleason, M. L., Wahle, E. A., and Oertel, B. 2007. Detection of sooty blotch and flyspeck fungi colonizing reservoir host plants in the Midwest U.S. (Abstr.) Phytopathology 97:S46.

13. Hemnani, K., Díaz Arias, M. M, Batzer, J. C., and Gleason, M. L. 2007. Completing Koch's postulates for newly discovered species in the sooty blotch and flyspeck complex. (Abstr.) Phytopathology 97:S46.

14. Hernández, S. M., Batzer, J. C., Gleason, M. L., Mueller, D. S., Dixon, P. M., Best, V., and McManus, P. S. 2004. Temperature optima for mycelial growth of newly discovered fungi in the sooty blotch and flyspeck complex on apples. (Abstr.) Phytopathology 94:S41.

15. Hickey, K. D. 1960. The sooty blotch and flyspeck disease of apple with emphasis on variation within Gloeodes pomigena (SCW.) Colby. Ph.D. dissertation, The Pennsylvania State University, University Park.

16. Johnson, E. M., Sutton, T. B., and Hodges, C. S. 1997. Etiology of apple sooty blotch disease in North Carolina. Phytopathology 87:88-95.

17. Kularatne, H. A. G. C., Lawrie, A. C., Barber, P. A., and Keane, P. J. 2004. A specific primer PCR and RFLP assay for the rapid detection and differentiation in planta of some $M y$ cosphaerella species associated with foliar diseases of Eucalyptus globulus. Mycol. Res. 108:1476-1493.

18. Latinović, J., Batzer, J. C., Duttweiler, K. B., Gleason, M. L., and Sun, G. 2007. First report of five sooty blotch and flyspeck fungi on Prunus americana in the United States. Plant Dis. 91:1685.

19. Leben, C. 1965. Epiphytic microorganisms in relation to plant disease. Annu. Rev. Phytopa- thol. 3:209-230.

20. Nielsen, K., Yohalem, D. S., and Funck Jensen, D. 2002. PCR detection and RFLP differentiation of Botrytis species associated with neck rot of onion. Plant Dis. 86:682-686.

21. Rolshausen, P. E., Trouillas, F., and Gubler, W. D. 2004. Identification of Eutypa lata by PCRRFLP. Plant Dis. 88:925-929.

22. Rosenberger, D. A. 1994. Summer disease control on apples. Annu. Rep. State Hortic. Soc. Mich. 124:80-86.

23. Schoch, C. L., Shoemaker, R. A., Seifert, K. A., Hambleton, S., Spatafora, J. W., and Crous, P. W. 2006. A multigene phylogeny of the Dothideomycetes using four nuclear loci. Mycologia 98:1041-1052.

24. Schweinitz, L. D. 1832. Dothidea pomigena. Page 232 in: Transactions of the American Philosophy Society, New Series, Philadelphia.

25. Sisson, A. J., Batzer, J. C., Duttweiler, K. B., and Gleason, M. L. 2007. Phenology of sooty blotch and flyspeck fungi on apples in Iowa (Abstr.) Phytopathology 97:S108

26. Sun, G., Zhang, M., Zhang, R., Ma, H., and Gleason, M. L. 2006. Wallemia-a genus newly recorded from China. Mycotaxon 95:277-280.

27. Sun, G. Y., Leandro, L. F., Batzer, J. C., Harrington, T. C., and Gleason, M. L. 2004. Specific PCR primers to identify sooty blotch and flyspeck fungi on apple in the Midwest U.S. (Abstr.) Phytopathology 94:S100.

28. Tarnowski, T. L., Batzer, J. C., Gleason, M. L., Helland, S., and Dixon, P. M. 2003. Sensitivity of newly identified clades in the sooty blotch and flyspeck complex on apple to thiophanatemethyl and ziram. Online. Plant Health Progress doi:10.1094/PHP-2003-1209-01-RS.

29. Vilgalys, R., and Hester, M. 1990. Rapid genetic identification and mapping of enzymatically amplified ribosomal DNA from several Cryptococcus species. J. Bacteriol. 172:4239-4246.

30. White, T. J., Bruns, T., and Taylor, J. 1990. Amplification and direct sequencing of fungal ribosomal RNA genes for phytogenetics. Pages 315-322 in: A Guide to Molecular Methods and Amplifications. M. A. Innis, D. H. Gelfand, J. J. Snisky, and J. W. White, eds. Academic Press, New York.

31. Williamson, S. M., and Sutton, T. B. 2000 Sooty blotch and flyspeck of apple: Etiology, biology, and control. Plant Dis. 84:714-724. 